\title{
Building a psychosocial and spiritual care service for children with cancer and their families
}

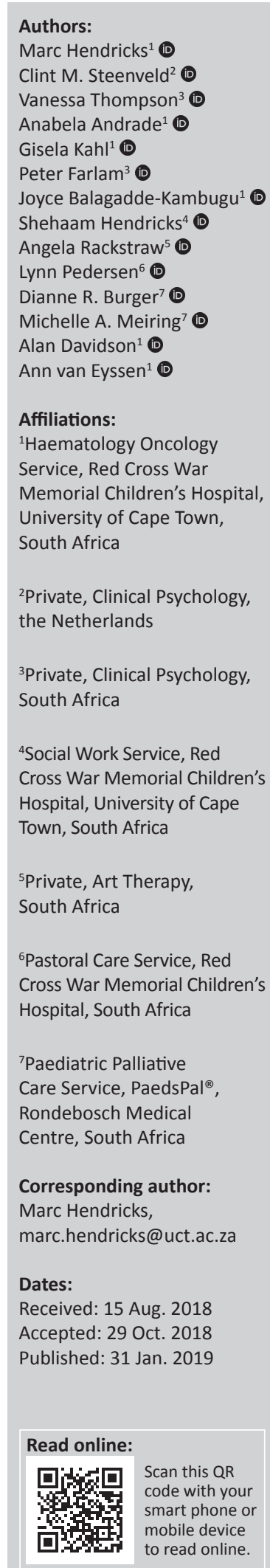

Background: Comprehensive, coordinated psychosocial, supportive and spiritual care is an essential component of the holistic care of childhood cancer sufferers and their families.

Aim: The authors detail the development and value of a multidisciplinary psychosocial care team as an essential adjunct to care of childhood cancer sufferers.

Methods: A historic preamble details a period during which psychosocial and supportive care was the sole province of the paediatric oncologists and social workers and describes that the process of creating a multidisciplinary psychosocial and spiritual care team has enhanced medical care.

Results: Each member of the psychosocial group describes their care philosophy and their role in the clinical setting. We also describe the critical role of the meeting as a teaching vehicle for oncology fellows.

Conclusion: This reproducible partnership between public and private sector practitioners, designed in a resource-constrained setting, affords a diverse and highly skilled group of professionals the opportunity to meet the medical, psychological, social and spiritual needs of patients and families as they transition through the care journey.

\section{Introduction}

Despite its privileged position compared to other paediatric services nationally, Red Cross War Memorial Children's Hospital's (RCWMCH) patient community faces the challenges of poverty, ${ }^{1}$ malnutrition, ${ }^{2,3}$ tuberculosis, ${ }^{4} \mathrm{HIV}^{5}$ domestic violence, ${ }^{6}$ rising methamphetamine (tik) abuse, ${ }^{7,8}$ gangsterism, ${ }^{9}$ the lack of paediatric community care resources ${ }^{3,10}$ and deepening economic austerity. These are magnified in the face of a cancer diagnosis and give rise to an array of psychosocial difficulties.

Historically, paediatric oncology units (POUs) in low- and middle-income (LMIC) countries have had to rationalise services in favour of medical care, ${ }^{11}$ despite clear evidence that the combined provision of standardised medical therapy together with psychosocial support positively impacts childhood cancer survival. ${ }^{12}$

The RCWMCH POU has strived to provide holistic care in alignment with the World Health Organization (WHO) definition for paediatric palliative care. ${ }^{13}$ Before 2009, palliative care and psychosocial support were provided by the oncologists and a social worker. Spiritual counsellors were available on call with no permanent on-site clinical psychology or palliative care services.

The number of newly diagnosed children with cancer seen at RCWMCH POU escalated from 105 per year in 2006 to 140 per year in 2009, having subsequently stabilised at 130 per year between 2010 and 2018. The surge was exacerbated by the concomitant rise in the migrant sickle cell disease population, given that an additional 40-50 patients per year present to the unit with haematological conditions (i.e. not cancer) of which sickle cell anaemia is a part. The unit recognised that growing patient numbers was negatively impacting its ability to provide psychosocial support. Negotiations between clinicians and administrators made it possible for patients with medical aid requiring outpatient chemotherapy to receive care at Rondebosch Medical Centre (geographically immediately adjacent to $\mathrm{RCWMCH}$ ), relieving pressure on nursing staff and finances.

How to cite this article: Hendricks $\mathrm{M}$, Steenveld CM, Thompson $\mathrm{V}$, et al. Building a psychosocial and spiritual care service for children with cancer and their families. S. Afr. j. oncol. 2019;3(0), a52. https://doi.org/10.4102/sajo.v3i0.52

Copyright: ( 2019. The Authors. Licensee: AOSIS. This work is licensed under the Creative Commons Attribution License. 
Historically, multidisciplinary meetings had been established to streamline the care of solid tumour patients. In 2012, monthly psychosocial meetings (PSM) began to better coordinate holistic psychosocial and spiritual care. Initially, the focus was end-of-life support for palliative care patients. Since then the scope of work has grown, and the team now includes three paediatric oncologists, two fellows, a social worker, a palliative care specialist paediatrician (PaedsPal ${ }^{\circledR}$ paediatric palliative care nongovernmental organisation [NGO]), a family counsellor (PaedsPal $\left.{ }^{\circledR}\right)$, an art therapist in private practice (with limited on-site funded hours), two clinical psychologists in private practice and the hospital's inter-faith spiritual care team.

We present our experience and care philosophies to date which have been developed and enhanced by our monthly PSM and which we regard as a product of successfully integrating carers and resources.

\section{Medical haematology oncology}

There are three qualified full-time paediatric oncologists jointly appointed by the University of Cape Town (UCT) and the Provincial Government of the Western Cape (PGWC) who oversee a full inpatient and outpatient service and provide a consultation service for colleagues across the Cape Town city metropole, Western Cape province and the country further afield in both state and private practice. Their activities include working in an integrated way to provide care for children following bone marrow transplantation, participating actively in a combined neuro-oncology service at Groote Schuur Hospital, doing local outreach clinic support at secondary level care facilities for children with sickle cell anaemia, providing a comprehensive haemophilia care service on site and running a limited hours private clinic for outpatient chemotherapy administration for funded patients at Rondebosch Medical Centre at GVI Oncology. This diverse landscape brings them into contact with children and families from every sector of society requiring not only medical care but also specialised supportive care, pain management and psychological and spiritual support. They bring these concerns to the PSM team for advice, direction and assistance.

While paediatric oncologists treat their patients, they also attend to the needs of parents, siblings and extended families. The diagnosis of a malignancy in a child is devastating and unanticipated, often more so to the family than the patient, who may be too young to comprehend the gravity of the situation. Children are guided by their parents, and thus the importance and complexity of breaking the bad news to parents, prior to speaking to the patient themselves in an age appropriate manner, is paramount to establishing a functional, trusting relationship with the family. ${ }^{14}$

Having taken time to explore family context, it is necessary at the outset to have a frank and honest discussion explaining the diagnosis, stage, prognosis and treatment options available for the child. The basis for the medical condition, the necessary tests and the treatment required are explained to parents and in time to patients, in so far as their age and their cognitive abilities allow. Parents and patients need time to process vast amounts of information, reflect on the information supplied to them and formulate their own questions. ${ }^{15}$

Children diagnosed with cancer enter a new world of painful procedures, unpleasant drug side effects (including nausea, fevers and sore mouths) and sleeping away from familiar surroundings. They miss their siblings, friends and pets. They miss crèche, their teachers and daily activities. The very young do not understand what is happening, but they feel their parents' pain and anxiety, which in turn drives their own. Older children long to be back at school and to participate in the activities they were involved in. Many are achievers and are disappointed and sad not to be able to participate. They may be preoccupied with procedurerelated pain and may have concerns about surviving, with treatment- or disease-related consequences like infertility or relapse. ${ }^{16,17,18}$ Oncologists need time to give them the opportunity to voice their fears, ask questions and have them answered honestly. ${ }^{19}$ In addition, online peer support groups may offer additional help to teenagers who spend long periods of time in isolation..$^{20,21}$

The child with cancer remains the paediatric oncologist's primary focus. It is the oncologist's duty to advocate for the best interests of the patient while including parents in all decisions. ${ }^{22}$ Often, the news that must be conveyed is not good in the case of advanced disease or disease progression. At these intersections, oncologists must balance the discussion of realistic expectations with one that would remove all hope. Hope is an essential part of resilience and removing all hope can be devastating for a child and their family. ${ }^{23}$ This may be a difficult balance to achieve but it may sometimes be necessary to reframe hope and create more realistic goals. Following discussions about realistic expectations, the treatment strategy proceeds. If a curative strategy has been adopted, it may be necessary to revisit this decision. Pursuing a curative strategy that causes recurrent hospitalisation and morbidity in the face of a poor outcome may not be in the patient's best interests. The idea of treatment without the intent to cure needs to be tactfully introduced so that parents and patients do not feel abandoned. Such a strategy focusses on ensuring that everything possible is done to optimise quality of life. Once the goals are clearly defined and articulated, it is easier to explain and justify treatment modalities. A palliative strategy may also include surgery, radiotherapy and chemotherapy and may deliver months or years of good quality life..$^{24}$ In an end-of-life (EOL) care setting, reframing goals helps to facilitate the thoughtful discussion of interventions to afford the patient the least suffering while placing patient dignity at the heart of the caring discussion..$^{25}$

\section{Social work}

A full-time social worker is dedicated to the oncology ward while covering other components of the system including 
non-accidental injury cases. The social worker meets all new families to assess their needs and refers patients through the PSM, coordinating care with other members of the team. He or she is responsible for coordinating patients' domiciliary placements to local Childhood Cancer Foundation (CHOC) houses and convalescent homes and regulates all activities with parent organisations and NGOs that impact families in the ward.

The social worker delivers a multitude of services which includes support and counselling. He or she assists in the management of relationship dynamics within families that arise because of the child's illness. These dynamics may be especially complex when a child is facing a terminal diagnosis. The social worker gains his or her initial understanding of the child and the family's circumstances by conducting a psychosocial assessment. This is followed by designing interventions which help families to tap into their own strengths and capabilities. ${ }^{26,27}$ Relationship and capacity building within families are also an important aspect of this work. Additional roles include the provision of material resources, arranging accommodation, initiating and overseeing support programmes, and assisting parents with the application for care dependency grants. Monitoring activities of the child and the family include daily ward and clinic visits. The social worker helps to support and strengthen the child's existing primary care arrangement. Up to a third of children seen in our service are cared for by extended family members or caregivers who arise out of either informal established care arrangements or formal court placements.

\section{Paediatric palliative care clinicians}

PaedsPal ${ }^{\circledR}$, a donor-funded NGO, provides a specialist consultative paediatric palliative care (PPC) service to children admitted to the RCWMCH. Although the South African government has recently developed both national and provincial palliative care policies, the discipline is yet to be recognised as a specialty, and the state is yet to fund services. The NGO has a Memorandum of Agreement with the hospital that allows its professionals who are registered with their respective regulatory bodies to see patients in a nonremunerated honorary capacity as an extension of the hospital's services. All team members' salaries are paid through fundraising efforts of the NGO and a small amount of funding is generated by the NGO from billing private patients.

The multidisciplinary team consists of two palliative care paediatricians, a medical officer, family counsellor, social worker, nurse and therapists (art, music and aromatherapies). The team sees patients across the hospital and not only in the oncology ward. Cancer patients are seen during admissions to $\mathrm{RCWMCH}$ but PaedsPal ${ }^{\circledR}$ also sees patients, siblings and families in an outpatient PPC clinic run from the Rondebosch Medical Centre and at home where capacity allows. Following the death of a child, bereavement support is also offered as needed. Key PPC offerings include assistance with complex pain and symptom management, advance care planning, linking families with community-based resources and assistance with terminal care. This section focuses on the clinical contributions of the PPC team as counselling and art therapy services linked to the NGO are discussed under other sections.

Palliative care is the science and art of lessening physical, psychosocial, emotional and existential suffering. Levels of suffering in paediatric oncology are significant. The essence of palliative care is described as 'the relief of suffering'.$^{28}$ According to parents interviewed after the death of their child from cancer, $89 \%$ of children suffered 'a great deal' in their last month of life. Of the children treated for specific symptoms, treatment was successful only in $27 \%$ of those with pain and $16 \%$ of those with dyspnoea. ${ }^{29}$

The 67th World Health Assembly resolution recognised, given the limited availability of palliative care services in much of the world, that there would be a need to create or strengthen health systems to include palliative care as an integral component of the treatment of people within the continuum of care. ${ }^{30}$

In the early days of integration of palliative and oncology teams, the oncology team was exposed to new ways of managing pain that they may not have been familiar with. The palliative care team had to learn to rely heavily on the knowledge and experience of the oncology team in terms of where the child and family were on their disease journey if the interventions they were advising were to be appropriate and acceptable. Given the high stigmatisation experienced by palliative care teams with their strong association with hospices and terminal care, the oncologists had to find creative ways of introducing the team so that patients and families were not scared off with early introductions and did not feel abandoned by their primary team.

\section{Family counselling}

A family counsellor employed by PaedsPal ${ }^{\circledR}$ is available on a referral basis through the PSM for families who are both inpatient and outpatient, irrespective of their mode of funding. Counsellors often meet families together with the treating oncologists in the clinical space to introduce new members of the care team to the family and child. These are planned interventions which are discussed prior to any introduction with the family.

Counselling is responsive to the spiritual, existential crises which manifest in the face of illness and death. It is described as care which recognises and responds to the needs of the human spirit in the face of trauma, ill health or sadness, while encouraging human contact in compassionate relationship. ${ }^{31}$

Counselling is offered in the inpatient and outpatient spaces where both state and privately funded patients enjoy access to this facility on a referral basis. The intention is to offer a safe, non-judgemental space to patients and their families. Counsellors set aside adequate time for such interactions, especially where there may be hesitancy or 
apprehension about open disclosure of true feelings and are required to be comfortable with the facilitation of individual or group discussions. He or she seeks to skilfully encourage participation while respecting those who do not wish to actively engage by being directive without being forceful and while managing potential conflict. Counsellors offer bereavement support and they assist families with problem-solving and building resilience. They also participate in debriefing staff members, which often organically unfolds in the monthly PSM.

\section{Clinical psychology}

Three clinical psychologists, all of whom operate in the private sector and who have a special clinical or research interest in children with chronic life-threatening illness, are part of the PSM. They receive referrals from the oncologists and other members of the team for patients, siblings and parents both inside and outside the PSM forum. They care for patients again irrespective of their mode of funding, often providing services pro bono for state-funded patients. Therapists often avail themselves to see children in hospital when they are too ill inside the oncology unit, including during paediatric intensive care unit (PICU) admissions. Private rooms are available for these sessions. Families who are funded can access care off site supported by their fund holder.

Children and teenagers often struggle to express their feelings about their illness and their changed circumstances. Therapy provides the opportunity to reflect on feelings. While this can be overwhelming at first, doing so in a secure and positive space allows patients to gain greater insight into themselves and to develop a deeper appreciation of their relationships with loved ones while improving their selfconfidence. ${ }^{32}$

Children and families may attend individual or family sessions. Chronic and terminal illnesses may potentially bring families together and even heal pre-existing rifts and difficulties but can equally present as a risk factor that aggravates pre-existing conflicts and/or produces new conflicts. An American study into the psychosocial effects of a recent cancer diagnosis on adolescents and young adult patients revealed that the negative effects mainly occupied the area of future planning (finances, having children and starting a family and career), body image and sense of autonomy or agency. The diagnosis also had a positive impact on things like relationships with loved ones and future life planning and purpose. Self-confidence may also be boosted as patients find that they have increased autonomy to influence the course of their treatment and illness. This is referred to as 'health competence' and is positively linked to good emotional, physical, social and family health in survivors. ${ }^{32}$

\section{Integrative psychotherapy}

The experience as a working participant in the PSM is articulated by the framework of an integrative relational approach to psychotherapy. ${ }^{33,34}$ The goal of this approach is to create positive changes in the lives of patients through the relationship between patient and therapist as well as with others. This idea may be extended to the relationships the patient has with his or her body, illness or diagnosis, and dying and death. Additionally, healthy aspects of the relationship the child has with other people close to him or her may be woven into the therapy process by way of bringing others into therapy sessions.

A focus on the child's relationships and manner of relating to others and to himself or herself helps the therapist to gain insight into the adaptive and maladaptive aspects of the child's relational patterns. By focusing on these, the therapist uses various techniques to restore balance by bringing together sometimes seemingly opposing parts of the child's functioning and character. This lays the foundation for a holistic coming together of people and parts. Just as integration and collaboration may be achieved with the patient and his or her family, so it may be achieved and mirrored by the carers.

\section{Conversations about death and dying}

The possibility of death and dying is already subsumed in the diagnosis of cancer and forces families to manage one of the most stringent life experiences, even in the face of having to maintain courage and fortitude for their children and each other. Anxiety towards death is considered the greatest psychological fear because it involves the unknown, especially a life not fully lived, as in the life of a child with cancer, or parents living without their child. . $5,36,37^{\text {These }}$ metaphysical concerns lie at the heart of this diagnosis and call psychologists to address their own belief systems, assumptions about cancer, treatment, survival and death. Parents, however, may feel that they have been punished or even that this experience is a result of unfinished business. Embracing the stages of grief, denial and isolation, anger, bargaining, depression and acceptance allows parents and children to begin where they are ${ }^{35}$ Another difficult aspect of children dying is that they are often more concerned about leaving their parents than they are about dying themselves. While children understand that the release from suffering may be great in death, they are not ready to leave without knowing their parents are well. As those who manage death and dying in adults, children often wait to say their goodbyes, see their loved ones or greet that special someone. What is perhaps incongruent is that death should be a developmental experience that we pass through at the end of an adult life, not in our childhood or adolescence. Additionally, there is the double bind of knowing that children may not survive the very treatment that may cure or heal them.

Parents may specifically ask clinicians not to mention the possibility of dying to their children as well as the fact that they have cancer. They may want the doctor to instil hope, so that their child will believe he or she could get better rather than giving in to despair. This idea of 'classic hope' as being in opposition to despair is in contrast with the concept of 
'reasonable hope'. Reasonable hope is arguably a more useful therapeutic tool in that it accommodates doubt, contradiction and despair while still seeking goals and pathways to them. The focus is on actions that the patient can take rather than any feelings that the patient may or may not be able to summon. ${ }^{38}$

\section{The younger child}

With younger children, it is noticeable that the emotional trauma they experience from their illness and medical procedures is often expressed indirectly in physical symptoms. Through therapy, children can explore their feelings which allows for a wider range of emotional expression than what can be achieved in the doctor's office. Play therapy can be an effective way not only to control pain but also to imbue it with shared psychological meaning, as well as giving children the opportunity to try new ways to face their circumstances. ${ }^{39}$ Playing also enables clients to try out new ways of being and new identities, where they have more power and control, rather than being on the receiving end of their illness and the medical interventions to combat this.

\section{Art therapy}

An art therapist is available to children in the ward through limited-hour donor funding to the burns unit and oncology ward as well as off site through PaedsPal ${ }^{\circledR}$ at Rondebosch Medical Centre. Sessions are available to patients, siblings and parents.

Art-making is closely aligned to play, which is the universal language of all children. Winnicott wrote that through play the child can be creative and use their whole personality and 'it is only in being creative that the individual discovers the self' and finds life worth living. So, in connecting to the self, one feels more energised and more alive. ${ }^{40}$

Art therapy is about a therapeutic relationship between child and therapist, and about art-making in a safe space. This often takes place at the bedside. A designated room would allow children to think and be creative without interruptions, where a relationship of trust and mutual respect can be nurtured. There would be an array of suitable art materials and the session would be tailored to the needs of the child. The child would be able to choose which materials to use, what to do and would even have a choice as to whether they wanted a session or not. If children are not able to draw or paint, it is the therapist's job to either assist or to do the artmaking on behalf of the child, asking for detailed directions from the child as to content.

Children are encouraged to take their completed artworks to the ward, so that this creative and tangible extension of themselves can be a reminder of their energy, creativity and independence. Depending on what was produced, it could also be a reminder of life which is beyond the hospital setting and their illness. Language and the spoken word are secondary to this because the focus is on art-making. Children are often able to express themselves better non-verbally and that may lead to more difficult but necessary conversations.

Parents and staff are offered a weekly crafting support group. Supporting parents better equips them to support their children. They are offered a time where they can focus on their own creativity and they find it both an important support and de-stressor. They are given an opportunity to air frustrations, worries and fears.

\section{Spiritual care}

A full-time chaplain, seconded to the hospital by the Anglican Church, has in turn developed a team of other volunteers diverse across cultures and religions, who have learned wisdom in collaboration with each other. It has been the team's consistent experience that simply being available has been valuable to parents, patients and the unit's staff alike. Support has been offered to the unit's staff individually and to groups. No matter how much objectivity is part of training, staff suffer stress and distress with these families.

For any person, a cancer diagnosis was never imagined and reflexively evokes images of death. Subliminally deep fear calls into question every assumption that the family has made about their future together.

The pastoral caregiver provides counselling which speaks to the meaning of life, its cause and effect. Our deepest longings and drives as humans are to love, to be loved, to grow and to be generative by investing in the growth of others. A parent's love drives him or her to give their child every opportunity to grow into all that they were created to be. How is it possible for any parent to comprehend the possibility of losing their child? A spiritual caregiver may help them in their processing of this crisis. Imponderable questions often arise: 'Why has this happened to me?', 'Why my child and not me?', 'Have I failed God in some way?', 'How do I pray now?'. What is prayer in this context and what divine interventions can one expect of God?' And if their child is not healed, what of their understanding of the divine now? How does this orientate or re-orientate their lives and their beliefs?

Pastoral care is also for the child if they are old enough to engage it. A Muslim pastoral carer was praying with a 5-yearold boy. When she had done so he asked her to go and pray for his friend in the next bed (whose family were Christian), as, in his estimation, his friend also needed prayer. She was very moved by this request. In this way, the children themselves become carers for each other and faith and prayer transcend boundaries of culture and faith expression. For the pastoral carer, this requires wisdom, sensitivity and readiness to learn from and to collaborate with other cultures and faith traditions.

Miracles do happen for those who believe in them. Some miracles relate to healing, in the phenomenal ways the human body fosters its own health; some in the advances in 
medicine that facilitates healing, others in the inexplicable healing that surpasses medical science; and some in the relational miracles of caring and generosity.

A father seated alongside his daughter who had died asked how we would choose this work. 'The work is not only about death, that is only a small part' was the response. Often, the most meaningful engagements happen at precisely such times.

\section{Haematology oncology fellows: Education and learning}

The unit trains registered paediatricians to become fully fledged clinical oncologists. A 2-year substantiative post is offered through the PGWC. Candidates are required to successfully complete an MPhil degree through UCT and a postgraduate certificate examination (written and oral) in medical oncology (Paediatrics) through the Colleges of Medicine of South Africa. The unit also trains candidates from the African Paediatric Fellowship Programme (APFP) who, contingent on donor funding and post availability, come for either 1- or 2-year tenures. Two-year applicants complete the certificate examination, while 1-year candidates may complete a Haematology Oncology Diploma at UCT. Palliative and supportive care is a core component of training which includes participation in the PSM.

Training in Paediatric Oncology is often principally directed at accurate diagnosis and treatment, with palliation and EOL care receiving less attention. ${ }^{41,42}$ Globally, doctors report inadequacies in training and lack of support from their institution. Curricula have been developed focusing on aspects such as pain and symptom management, communication skills, ethical principles and bereavement. ${ }^{43,44}$ In one study, it was noted that few fellowship programmes held evidence-based journal clubs on palliative care and pain management issues, and $69 \%$ of programmes did not offer any journal clubs on palliative care issues throughout their fellowship. ${ }^{45}$

Oncologists give bad news as frequently as 35 times each month in their practice. $^{46}$ Done well, communication fosters enhanced understanding, more accurate symptom disclosure, better adherence to planned treatments, decreased psychological distress, reduced feelings of abandonment and improved satisfaction with care. Both families and oncologists have expressed dissatisfaction with the quality of communication. ${ }^{45}$ This deficiency has been attributed to inadequacies in communication skills training in the fellowship curricula ${ }^{47}$ overreliance on role modelling and failure to utilise best practices. Sixty-four per cent of chief resident respondents agreed that they were only adequately trained to communicate bad news to a parent, while only $31 \%$ felt they were adequately trained to communicate bad news to a child. ${ }^{48}$

It is also essential to look after individual staff members caring for children with cancer. ${ }^{49}$ High patient numbers, cumulative deaths and witnessing suffering can ultimately lead to burnout. More than half of oncology fellows experience burnout in at least one domain - emotional exhaustion, depersonalisation or personal accomplishment. ${ }^{50}$ An evaluation of fellowship programmes in the USA showed that more than $50 \%$ do not have a system for debriefing following the death of a child. ${ }^{51}$ Such a system would allow for a continued sense of appreciation and sense of importance of one's role in the child's care and may prevent burnout. ${ }^{52}$

The Paediatric Medical Oncology certificate of the College of Medicine of South Africa requires the candidate to have a sound understanding of the principles of psychosocial support for the child with cancer and their family. ${ }^{53}$ A palliative care curriculum has recently been made available to paediatric oncology trainees associated with UCT. This predominantly adult-focused course is sponsored by the Cancer Association of South Africa (CANSA), involves faceto-face teaching, web-based reading and formal assessments and still has relevance for paediatric settings. ${ }^{54}$

\section{Conclusion}

No single practitioner or caregiver sees the entire whole of a patient's life. A team of caregivers, where each member looks at the patient from a unique perspective and is simultaneously open to their diverse, if not divergent perspectives, enhances the wholeness of treatment and creates real value for the patient. The PSM exemplifies how different disciplines have come together to produce of a new way of thinking and working that is not merely the sum of its parts. ${ }^{33}$

The formation of our PSM team required patience to understand the individual strengths of each member and to relinquish control to a member of the team who was best suited to lead care in any given circumstance. This was a difficult part of the initial process and has been an evolution during which every member of the team has had to learn to reframe their caring style to embrace a less paternalistic, hierarchical approach in favour of more open relationships which are operationally more inclusive, more fluid, more forgiving and which build trust. The team now operates with a deeper understanding of each other's skills, limitations and stressors and this has allowed for a supportive environment where mutual respect, rather than ego, has taken centre stage.

Importantly, it also serves as a teaching space for fellows and for inter-disciplinary academic growth through a continuing professional development (CPD) accredited journal club and provides opportunities to present at local and international conferences and events across disciplines. It provides opportunities for rich discussions and deeper engagement around more nuanced cases, while simultaneously opening avenues for learning and debriefing. Collective debriefing is an important part of building resilience and sharing the burden of care and has opened a healthy space to access 
shared humour as an occasional but necessary antidote to the high emotional cost of the work.

We hope that by sharing our experience and care philosophies we have demonstrated that intersectoral public-private models of care are not only possible but also essential to bolster deficits in the public health system and may provide pioneering pilots which can dovetail with the emerging implementation of the National Health Insurance policy. We believe this model is reproducible and sustainable. Our success should mitigate in favour of the allocation of resources for the delivery of holistic care to all children with cancer and their families, irrespective of their financial resources, particularly as it pertains to palliative care services.

\section{Acknowledgements Competing interests}

The authors declare that they have no financial or personal relationships that may have inappropriately influenced them in writing this article.

\section{Authors' contributions}

M.H. wrote the introduction and conclusion and did substantial editing in preparing the document for publication. A.v.E and A.D. wrote the haematology oncology section. S.H. wrote the social work section. M.A.M wrote the palliative care section. D.R.B. wrote the family counselling section. A.R. wrote the art therapy section. C.M.S., V.T. and P.F. co-authored the psychology section. C.M.S. also contributed to the conclusion and helped with final editing. L.P. wrote the spiritual care section. A.A., G.K and J.B.K. wrote the education and learning section. All authors were involved in revisions and editing of the article.

\section{References}

1. Economics and Poverty - Western Cape Government. [homepage on the Internet]. [cited 2017 Dec 13]. Available from: https://www.westerncape.gov.za/ text/2005/12/12_soer_economics_optimised_05.pdf

2. Bradshaw D, Bourne D, Nannan N. South African Medical Research Council. What are the leading causes of death among South African children? No. 3 December 2003 [homepage on the Internet]. [cited 2017 Dec 14] Available from: http:// www.mrc.ac.za/bod/reports.htm

3. Amery J, editor. Children's palliative care in Africa [homepage on the Internet] Chapter 1. pp. 23-25. [cited 2017 Dec 14] Available from: http://www.in.bgu.ac.il/ en/fohs/communityhealth/Documents/PalliativeProt/children's_Palliative_Care_ In_Africa_Full_Text.pdf

4. Kapp C. Crystal meth boom adds to South Africa's health challenges. Lancet 2008;371(9608):193-194. https://doi.org/10.1016/S0140-6736(08)60120-8

5. Western Cape Government: Health. 2020 Strategic Framework. The future of health in the Western Cape: A draft framework for dialogue [homepage on the Internet]. November 2011. pp. 47-50. [cited $2017 \mathrm{Dec} 14]$. Available from: https:// www.westerncape.gov.za/other/.../healthcare_2020_-_9_december_2020.pdf

6. Abrahams N, Jewkes R, Laubscher R, Hoffman M. Intimate partner violence: Prevalence and risk factors for men in Cape Town, South Africa. Violence Vict. 2006 Apr;21(2):247-264. https://doi.org/10.1891/vivi.21.2.247

7. Wechsberg WM, Luseno WK, Karg RS, et al. Alcohol, cannabis, and methamphetamine use and other risk behaviours among black and coloured South African women: A small randomized trial in the Western Cape. Inter J Drug Pol. 2008;19(2):130-139. https://doi.org/10.1016/j.drugpo.2007.11.018

8. Tuberculosis in Cape Town - Desmond Tutu HIV Foundation [homepage on the Internet]. [cited 2017 Dec 13] Available from: https://www. desmondtutuhivfoundation.org.za/tuberculosis-cape-town/

9. Gangsterism in the Western Cape: Briefing by SAPS [homepage on the Internet]. [cited 2017 Dec 13]. Available from: https://pmg.org.za/committeemeeting/1033/
10. Downing J, Marston J, Boucher S. Children's palliative Care in Africa [homepage on the Internet]. Australian J Cancer Nurs. Dec 2010;11(2):3-6 and 8-10. [cited 2017 Dec 13]. Available from: http://search.informit.com.au/documentSummary;dn= Dec 13]. Available from: http://search.inform
868185643952930;res=IELHEA ISSN1441-2551

11. Kruger $M$, Hendricks $M$, Davidson A, et al. Childhood Cancer in Africa. Pediatr Blood Cancer. 2014;61(4):587-92. https://doi.org/10.1002/pbc.24845

12. Ribiero RC, Pui C. Saving the children - improving childhood cancer treatment in developing countries. NEJM. 2005;352(21):2158. https://doi.org/10.1056/NEJMp 048313

13. World Health Organization. WHO definition of palliative care. [cited 2017 Dec 13] Available from: http://www.who.int/cancer/palliative/definition/en/

14. Mack JW, Grier HE. The day one talk. J Clin Oncol. 2004;22(3):563-566. https:// doi.org/10.1200/JCO.2004.04.078

15. Chanock S. Reflections on events surrounding the time of diagnosis in pediatric oncology. J Pediatr Hematol Oncol. 2001;23(4):211-212. https://doi.org/10.1097/ 00043426-200105000-00006

16. De Chico Cicogna E, Nascimento LC, De Lima RAG. Children and adolescents with cancer: Experiences with chemotherapy. Rev Lat Am Enfermagem. 2010;18(5):864-872. https://doi.org/10.1590/S0104-11692010000500005

17. Momani TG, Mandrell BN, Gattuso JS, West NK, Taylor SL, Hinds PS. Children's perspective on health-related quality of life during active treatment for acute lymphoblastic leukemia: An advanced content analysis approach. Cancer Nurs. 2015;38(1):49-58. https://doi.org/10.1097/NCC.0000000000000174

18. Calaminus G, Weinspach S, Teske C, Göbel U. Quality of life in children and adolescents with cancer. First results of an evaluation of 49 patients with the PEDQOL questionnaire. Klin Pediatr. 2000; 212(4):211-215. https://doi. org/10.1055/s-2000-9679

19. Marcus J. Psychosocial issues in pediatric oncology. Ochsner J. 2012;12(3): 211-215.

20. Thompson CM, Crook B, Love B, Macpherson CF, Johnson R. Understanding how adolescents and young adults with cancer talk about needs in online and faceto-face support groups. J Health Psychol. 2016;21(11):2636-2646. https://doi. org/10.1177/1359105315581515

21. Kent EE, Smith AW, Keegan TH, et al. Talking about cancer and meeting peer survivors: Social information needs of adolescents and young adults diagnosed with cancer. J Adolesc Young Adult Oncol. 2013;2(2):44-52. https://doi. org/10.1089/jayao.2012.0029

22. Salmon P, Hill J, Ward J, Gravenhorst K, Eden T, Young B. Faith and protection: The construction of hope by parents of children with leukemia and their oncologists. Oncologist. 2012;17(3):398-404. https://doi.org/10.1634/theoncologist.2011-0308

23. Weaver MS, Heinze KE, Kelly KP, et al. Palliative care as a standard of care in pediatric oncology. Pediatr Blood Cancer. 2015;62 Suppl 5:S829-S833. https:// doi.org/10.1002/pbc.25695

24. Whitney SN, Ethier AM, Frugé E, Berg S, McCullough LB, Hockenberry M. Decision making in pediatric oncology: Who should take the lead? The decisional priority in pediatric oncology model. J Clin Oncol. 2006;24(1):160-165. https://doi.org/ 10.1200/JCO.2005.01.8390

25. Szynkarsky D. Role of social work in the field of oncology [homepage on the Internet]. MSW Dept of Social Service, Adult Sites, McGill University Health Centre. [cited 2018 Jan 29]. Available from: https://cancerkn.com/the-role-ofsocial-workers-in-the-field-of-oncology/ Posted August 16, 2011.

26. Theoretical Approaches Social Work Theory/Social Work License Map (scholarly articles for family Systems Theory Social Work) [homepage on the Internet]. [cited 2018 April 10]. Available from: https://socialworklicensemap.com/theoreticalapproaches-social-work-systems-theory/

27. Perkins DD, Zimmerman MA. Empowerment theory, research and application. Am J Com Psychol. 1995;23(5):569-578. https://doi.org/10.1007/BF02506982

28. Doyle D. The essence of palliative care. A personal perspective. London: National Council for Hospice and Specialist Palliative Care; 2004. ISBN: 1898915369

29. Wolfe J, Grier HE, Klar N, et al. Symptoms and suffering at the end of life in children with cancer. NEJM. 2000:342(5):326-333. https://doi.org/10.1056/NEJM20000 2033420506

30. WHA 67.9. Strengthening of palliative care as a component of comprehensive care throughout the life course [homepage on the Internet]. [cited 2018 Apr 03]. Available from: http://apps.who.int/medicinedocs/documents/s21454en/s21454en.pdf

31. Levison C. Spiritual care matters: An introductory resource for all NHS Scotland Staff [homepage on the Internet]. February 2009. [cited 2018 March 14]. Available from: http://www.nes.scot.nhs.uk/media/3723/spiritualcaremattersfinal.pdf

32. Bellizzi KM, Smith A, Schmidt $S$, et al. The Adolescent and Young Adult Health Outcomes and Patient Experience (AYA HOPE) Study Collaborative Group. (2012). Positive and negative psychosocial impact of being diagnosed with cancer as an adolescent or young adult. Cancer. 2015;2012:5155-5162.

33. Wachtel PL. An integrative relational point of view. Psychotherapy 2014;51(3):342-349. https://doi.org/10.1037/a0037219

34. Ben-Shahar AR. Touching the relational edge: Body psychotherapy [homepage on the Internet]. [cited 2018 Feb 27]. [Kindle DX version. Available from www. amazon.com]. London: Karnac Books; 2014

35. Heidegger M. Being and time. San Francisco, CA: Harper; 1962.

36. Kübler-Ross E. On death and dying. London: Tavistock; 1969.

37. Chopra D. Life after death: The book of answers. Reading, United Kingdom: Random House; 2006.

38. Weingarten K. Reasonable hope: Construct, clinical applications, and supports. Fam Proc. 2010;49:5-25. https://doi.org/10.1111/j.1545-5300.2010.01305.x 
39. Scarponi P, Pession A. Play therapy to control pain and suffering in pediatric oncology. Front Pediatr. 2016;4:132. https://doi.org/10.3389/fped.2016.00132

40. Winnicott DW. Playing and reality. London: Psychology Press, 1971; p. 54.

41. Raney RB, O'Donnell JF, Brooks CM, et al. Pediatric oncologists' assessment of oncology education in U.S. medical schools: Cancer Education Survey II. J Cancer Educ. 1994;9:141-144.

42. Contro NA, Larson J, Scofield S, Sourkes B, Cohen HJ. Hospital staff and family perspectives regarding quality of pediatric palliative care. Pediatrics. 2004;114:1248-1252. https://doi.org/10.1542/peds.2003-0857-L

43. Weissman DE, Block SD. ACGME requirements for end-of-life training in selected residency and fellowship programs: A status report. Acad Med. 2002;77:299-304. https://doi.org/10.1097/00001888-200204000-00008

44. Dittrich C, Kosty M, Jezdic S, et al. ESMO/ASCO recommendations for a global curriculum in Medical Oncology Edition 2016. ESMO Open. 2016;29(1)5:e000097. eCollection 2016. https://doi.org/10.1136/esmoopen-2016-0000

45. Roth M, Wang D, Kim M, Moody K. An assessment of the current state of palliative care education in pediatric hematology/oncology fellowship training. Pediatr Blood Cancer. 2009;53:647-651. https://doi.org/10.1002/pbc.22110

46. Buss MK, Lessen DS, Sullivan AM, Van Roenm, Arnold RM, Block SD. Hematology/ Oncology fellows' training in palliative care. Cancer. 2011;117(18):4304-4311. https://doi.org/10.1002/cncr.25952

47. Horlait M, Chambaere K, Pardon K, Deliens L, Van Belle S. What are the barrier faced by medical oncologists in initiating discussion of palliative care? A qualitative study in Flanders, Belgium. Support Care Cancer. 2016;24(9):3873-3881. https:// doi.org/10.1007/s00520-016-3211-5
48. Spinetta JJ, Jankovic M, Masera G, et al. Optimal care for the child with cancer: A summary statement from the SIOP Working Committee on Psychosocial Issues in Pediatric Oncology. Pediatr Blood Cancer. 2009 Jul;52(7):904-907. https://doi.org/ in Pediatric Oncology.

49. Schellhorn S, Lessen DS, Levine RL, et al. Palliative care training and burnout in oncology fellows. J Clin Oncol. 2009;27(15S):9450.

50. Wiener L, Oppenheim D, Breyer J, Battles H, Zadeh AS, Patenaude AF. A worldview of the professional experiences and training needs of pediatric psycho-oncologists. Psycho-oncology. 2012;21(9):944-953. https://doi.org/10.1002/pon.3064

51. Spinetta JJ, Jankovic M, Ben Arush MW, et al. SIOP working committee on psychosocial issues in pediatric oncology: Guidelines for the recognition, prevention, and remediation of burnout in health care professionals participating prevention, and remediation of burnout in health care professionals participating in the care of children with cancer. Med Pediatr Oncol. 2000; 35:122-125. https://doi.
0. CO; $2-J$

52. Cert Medical Oncology (SA) Paed Portfolio [homepage on the Internet]. 2018 [cited 2018 Mar 24]. Available from: https://www.cmsa.co.za/view_exam.aspx? QualificationID=91

53. Scrimgeour E, Marston J, Boucher S. Children's palliative care in South Africa - The facts [homepage on the Internet]. October 2010 [cited 2018 April 03]. Available from: http://www.icpcn.org/downloads/Children_s_Palliative_Care_in_South_ Africa_-_The_Facts.pdf

54. Cancer Association of South Africa. Evaluating Palliative Care training in the oncology registrar program [homepage on the Internet]. [cited 2018 March 14]. Available from: http://www.cansa.org.za 